\title{
"Semente para Luta": ativismos, direito à saúde e enfrentamentos de pessoas LGBTI na pandemia da covid-19
}

"Seed for Fight": activism, right to health and confrontations of LCBTI people in the covid-19 pandemic

\author{
Bruno Kauss $^{\mathrm{a}}$ \\ (D) https://orcid.org/0000-000I-8753-5574 \\ E-mail: kauss.brunoळgmail.com \\ Maurício Polidoro ${ }^{b}$ \\ (D) http://orcid.org/0000-0002-7278-0718 \\ E-mail: mauricio.polidoroळgmail.com

\section{Adriano Costa ${ }^{a}$} \\ (D) https://orcid.org/0000-0002-1207-5320 \\ E-mail: adrianohcaetano®gmail.com

\section{Daniel Canavese ${ }^{c}$} \\ (D) http://orcid.org/0000-0003-0110-5739 \\ E-mail: daniel.canaveseळgmail.com \\ aniversidade Federal do Rio Grande do Sul. Porto Alegre, RS, Brasil. \\ 'Instituto Federal do Rio Grande do Sul. Porto Alegre, RS, Brasil. \\ 'Universidade Federal do Rio Grande do Sul. Departamento de \\ Saúde Coletiva. Porto Alegre, RS, Brasil.
}

\section{Resumo}

Este trabalho investiga como a saúde de pessoas lésbicas, gays, bissexuais, travestis, transexuais e intersexuais (LGBTI) tem sido afetada no contexto da pandemia da covid-19, por meio da percepção de ativistas da sociedade civil organizada, no Estado do Rio Grande do Sul (RS), Brasil. Realizou-se uma análise qualitativa, que reporta dados preliminares de um estudo maior sobre a Política Nacional de Saúde LGBTI. O levantamento foi feito entre maio e julho de 2020, com a aplicação de entrevistas realizadas online. 0 enfoque se deu sobre as percepções, as experiências individuais e coletivas de ativistas sobre a temática da saúde LGBTI, em meio ao atravessamento da pandemia da covid-19. Constataram-se efeitos sobre a mobilização comunitária; o acesso aos serviços de saúde; a saúde mental; e as situações de violência e proteção social. Conclui-se que as intervenções coletivas de pessoas LGBTI são fundamentais em contextos de crise sanitária e dão suporte à garantia do direito à saúde e preservação de políticas públicas a esta população. Palavras-chave: LGBTI; Covid-19; Movimentos Sociais; Direito à Saúde.

\section{Correspondência}




\section{Introdução}

This study investigates how the health of lesbian, gay, bisexual, transvestite, transsexual, and intersex (LGBTI) people has been affected in the context of the covid-19 pandemic, by the perception of organized civil society activists in the state of Rio Grande do Sul, Brazil. It is a qualitative analysis, which reports data from a larger study on the National Health Policy LGBTI. The survey was conducted between May and July 2020, with the application of online interviews. The focus was on the perceptions, individual and collective experiences of activists on the theme of LGBTI health, amidst the covid-19 pandemic. We found effects on community mobilization; access to health services; mental health; and situations of violence and social protection. The study concluded that the collective interventions of LGBTI people are fundamental in contexts of health crisis and support the guarantee of the right to health and the preservation of public policies for this population. Keywords: LGBTI; Covid-19; Social Movements; Right to Health.
A covid-19 ou 2019-nCoV é uma infecção respiratória aguda, ocasionada pelo vírus SARS-CoV-2, inicialmente identificada na província de Hubei, China, em dezembro de 2019 (Wu et al., 2020). Em 30 de janeiro de 2020, a Organização Mundial da Saúde (OMS) declarou o surto ocasionado pelo SARS-CoV-2 como Emergência de Saúde Pública de Importância Internacional (ESPII); e, em 11 de março de 2020, devido à rápida propagação geográfica do vírus, reclassificou-o como uma pandemia global.

Àmedida que a covid-19 se espalha pelo mundo e, em atenção às demandas da população LGBTI, a Comissão Interamericana de Direitos Humanos (CIDH), no âmbito de sua Unidade de Coordenação de Resposta Rápida e Integrada à crise da pandemia de covid-19, insta os Estados a garantir direitos às pessoas LGBTI nas medidas adotadas para conter a pandemia, a exemplo do direito à saúde, da equidade e da não discriminação (OEA, 2020; UN, 2020). Diante das dificuldades impostas às populações vulneráveis, destaca-se aqui a atuação do movimento representativo de lésbicas, gays, bissexuais, travestis, transexuais e intersexuais (LGBTI), que historicamente articula ações no espaço público, subverte sistemas (Trevisan, 2018), desafia padrões e contribui para a garantia de direitos e políticas de saúde, a exemplo do enfrentamento à aids (Grangeiro; Silva; Teixeira, 2009).

$\mathrm{Na}$ década de 1980, com o registro dos primeiros casos de aids, parte de ativistas se articularam numa expressiva resposta comunitária (Grangeiro; Silva; Teixeira, 2009). Nos anos 2000, ações voltadas à promoção de cidadania e direitos humanos marcaram uma mudança no enfoque das políticas LGBTI (Mello; Avelar; Maroja, 2012). A criação do Programa Brasil Sem Homofobia (BSH), lançado em 2004, refletiu discussões entre o Governo Federal e os movimentos sociais, principalmente em relação ao enfrentamento da discriminação e violência contra pessoas LGBTI. A Política Nacional de Saúde LGBT (PNSLGBT), instituída pela Portaria $n^{\circ}$ 2.836, de 2011, é um marco no reconhecimento das demandas LGBTI, em conformidade com as diretrizes do BSH, dos princípios da Constituição Federal de 1988 e da Carta dos Direitos dos Usuários do Sistema Único de Saúde (SUS). 
Com vistas a apoiar a implementação de estratégias de saúde às pessoas LGBTI na região sul do Brasil, nasceu o estudo: "A Política Nacional de Saúde Integral de Lésbicas, Gays, Bissexuais, Travestis e Transexuais (LGBT): estratégias de análise, avaliação e formação para o aprimoramento do Sistema Único de Saúde”, com sede no Departamento de Saúde Coletiva, da Universidade Federal do Rio Grande do Sul (UFRGS) e aprovado pelos devidos comitês de ética em pesquisa. A partir do estudo maior, investigou-se como a saúde LGBTI foi afetada no contexto da pandemia da covid-19, por meio da percepção de ativistas da sociedade civil organizada, no estado do Rio Grande do Sul (RS). Toma-se como pressuposto, a importância dos movimentos sociais no diagnóstico de questões sensíveis à saúde de pessoas LGBTI e no apoio à implementação da PNSLGBT.

Os movimentos sociais ou a sociedade civil organizada são aqui compreendidos como atores que produzem "ações sociais coletivas de caráter sociopolítico e cultural que viabilizam formas distintas da população se organizar e expressar suas demandas" (Gohn, 2011, p. 335). Tais ações buscam, a partir de instrumentos não institucionais de pressão, como passeatas, advocacy, ciberativismo, entre outros, gerar mudanças na ordem social, influenciar os resultados de processos sociais e políticos que envolvem valores ou decisões de governos e referentes às políticas públicas (Machado, 2007; Deslandes, 2018).

A investigação explorou a percepção dos atores em três eixos principais: mobilização comunitária voltada à garantia do direito à saúde das pessoas LGBTI; os efeitos da covid-19 sobre a saúde e o incremento das violências; e os desafios à implementação da PNSLGBTI. Na interpretação dos dados, observou-se a proposta teórica de Parker (1998), o qual sugere três correntes principais para compreender o campo das intervenções coletivas: (1) da mobilização comunitária, que objetiva desenvolver ou incrementar a ação de ativistas e grupos sociais; (2) da intervenção estrutural, que incide sobre condições do meio, com o intuito de facilitar a ação das pessoas; (3) e da transformação social e empoderamento coletivo, que busca promover a conscientização sobre as condições de opressão e iniquidades, por meio de processos educativos e de respeito aos direitos humanos.

\section{Metodologia}

A abordagem da pesquisa é qualitativa (Yanow, 2007) e utilizou técnicas de revisão de literatura e entrevistas com ativistas de movimentos sociais. Na condução das entrevistas, observou-se as possibilidades de produção do conhecimento e interpretações a partir dos significados atribuídos pelos atores nas relações mediadas pelo uso de tecnologias (Hine, 2008; Latour, 2012). Nesse aspecto, buscou-se explorar as potencialidades da entrevista realizada em meio digital, dado o cenário de restrições sanitárias imposto pela covid-19.

As entrevistas foram realizadas entre maio e julho de 2020 , por meio do sistema de webconferência MConf e Google Meet. Tal preferência se justifica diante do contexto da pandemia da covid-19, no intuito de primar pela segurança dos participantes e pesquisadores envolvidos, observando as medidas sanitárias de isolamento físico.

Realizaram-se sete entrevistas com pessoas que se autoidentificaram como ativistas de movimentos sociais, sobre questões relacionadas à população LGBTI. A seleção dos(as) participantes foi realizada por conveniência e disponibilidade, levando em consideração: a trajetória no ativismo em relação à saúde LGBTI; a diversidade étnica e geográfica dos(as) participantes, no estado do RS; e a forma de atuação privilegiada - coletiva, em organizações da sociedade civil; ou de forma individual por meio de ativismo digital ou ciberativismo. 
Quadro I - Caracterização das pessoas entrevistadas e forma de atuação principal no movimento LGBTI

\begin{tabular}{|c|c|c|c|c|c|}
\hline Nome & Idade & Raça/Cor e Etnia & Identidade de Gênero & Orientação Sexual & Atuação Principal \\
\hline Amanda & 24 & Branca & Mulher cisgênera & Lésbica & Coletiva \\
\hline Ana & 23 & Branca & Mulher trans e travesti & Bissexual & Individual \\
\hline Cristina & 40 & $\begin{array}{l}\text { Parda, indigena, } \\
\text { etnia Terena }\end{array}$ & Mulher trans & Não informou & Coletiva \\
\hline Marcos & 38 & Parda & Homem cisgênero & Homossexual & Individual \\
\hline Paola & 50 & Negra & Mulher cisgênera & Lésbica & Coletiva \\
\hline Rosa & 51 & Branca & Mulher cisgênera & Heterossexual & Coletiva \\
\hline Tamara & 20 & $\begin{array}{l}\text { Parda, indigena, } \\
\text { Mbya Guarani }\end{array}$ & Mulher cisgênera & Bissexual & Coletiva \\
\hline
\end{tabular}

Seis entrevistas foram realizadas em dupla, contando com a presença de um mediador e dois apoiadores para a discussão. Tal opção foi feita a fim de conectar experiências diversas de ativismos e fomentar um debate em relação à temática das políticas de saúde LGBTI. Apenas uma entrevista foi realizada individualmente, devido à indisponibilidade de agenda da pessoa convidada.

O roteiro das entrevistas buscou explorar a trajetória dos entrevistados no ativismo; as ações atuais realizadas; o impacto da covid-19 nas ações realizadas; quais ações têm sido realizadas no contexto da covid-19 e os desafios para além da covid-19.

As autorizações foram concedidas por meio de Termo de Consentimento Livre e Esclarecido (TCLE), enviado previamente para cada participante e assinado digitalmente. A investigação buscou observar os princípios éticos presentes na Resolução $\mathrm{n}^{\circ} 466$ do Conselho Nacional de Saúde (CNS), de 12 de dezembro de 2012 (MS/RES. 466/2012). Os nomes dos participantes da pesquisa foram alterados para garantir a confidencialidade.

A transcrição, codificação e análise do material empírico foi realizada com o auxílio do software NVivo.

\section{Resultados e Discussão}

\section{Corpos e Movimentos}

Ana começou a se envolver no ativismo LGBTI ao ingressar na universidade pública. Ela percebe uma inexpressiva representatividade de pessoas trans e travestis no espaço universitário. Na sua época de graduação, foi a primeira aluna trans na faculdade que cursava. Hoje, atua em questões relacionadas à saúde de pessoas trans e travestis, e se interessa também por saúde indígena e outras conexões.

Eu não sabia que eu era ativista, mas acabava sendo uma figura política, porque a partir do momento que tem uma trans numa universidade, muitas vezes, a gente acaba sendo o fenômeno só porque existe. (Ana, mulher trans e travesti, bissexual, branca, 23 anos)

Ana considera-se ativista digital e privilegia a atuação individual e o ciberativismo. Em muitos espaços, ela e outros ativistas enfrentam situações de pouca representatividade, agravadas pela hostilidade à diversidade sexual e de gênero.

$\varepsilon$ aí a gente não tem um Estado que tá preocupado com a população em geral, e muito menos com as populações marginalizadas, que entra a população LGBT. E pensando na população LGBT, lésbicas são super invisibilizadas. Super super super invisibilizadas. (Amanda, mulher cisgênera, lésbica, branca, 24 anos)

A invisibilidade das demandas é uma constante. A saúde sexual de mulheres lésbicas, por exemplo, especialmente de lésbicas jovens e negras, tem sido pouco abordada, em parte devido à crença de que mulheres em relacionamentos homossexuais 
têm risco baixo ou inexistente para o HIV e outras infeções sexualmente transmissíveis (IST) (Matebeni et al., 2009). No entanto, as evidências sobre a saúde de mulheres lésbicas sinalizam o contrário (Andrade et al., 2020), ao encontro da percepção da entrevistada.

Como as mulheres lésbicas que vivem com HIV são invisibilizadas, mesmo dentro da pauta do HIV/ aids. Muito, por não serem um número significativo. Tu não tem um " $n$ " significativo que vai ter uma prevalência numa pesquisa, e aías tuas vivências, elas não têm importância, as suas especificidades não são trabalhadas, as políticas não pensam a tua vivência. Aí volta essa questão de um modo biomédico. (Amanda, mulher cisgênera, lésbica, branca, 24 anos)

Marcos atua com ativismo digital e de forma individual, difundindo informações sobre prevenção ao HIV e enfrentamento ao estigma e à discriminação. Ele narra que vivenciou muitas situações de violência relacionadas à orientação sexual na cidade em que reside, localizada na região de fronteira e no interior do RS. A identificação com o ativismo LGBTI possui relação com a descoberta da sorologia positiva para o HIV. Ele percebe que o HIV praticamente lhe "tirou" de um segundo armário e que a aproximação com o movimento negro local o ajudou nas primeiras ações como ativista.

\section{Efeitos da covid-ıg na Saúde LGBTI}

Os relatos demonstram que a pandemia da covid-19 gerou mudanças nos ativismos coletivos e individuais. A reorganização de parte dos ativistas no espaço público foi um dos efeitos, notadamente entre aqueles que privilegiavam ações coletivas e presenciais. Se antes a articulação desses ativistas era realizada majoritariamente em espaços como a rua, bares, cafés, entre outros, agora, o ambiente virtual foi estabelecido como o principal espaço de encontro.

A gente também, pela vivência, pela pesquisa, a gente entende que a juventude se organiza muito no espaço público, né? $\varepsilon$ aí o espaço público entendido, conforme outros trabalhos também, a rua, o bar, essas referências em torno da escola, são espaços de sociabilidade. E agora tu não tem esse espaço, tu não tá podendo tá nesse espaço. (Paola, mulher cisgênera, lésbica, negra, 50 anos)

Observa-se o conflito geracional provocado pela necessidade de adequação dos ativismos ao contexto da pandemia, bem como da manutenção de ações e redes pré-estabelecidas. Além da suspensão da sociabilidade presencial, constata-se que a execução das ações também foi afetada pela covid-19.

Em todos os sentidos: no momento de não conseguir trabalhar direito, as nossas atividades que nós tínhamos pela rede com várias programações tiveram que ser suspensas. Até a gente conseguirse adaptar nesse novo contexto de realidade virtual, agora que eu tô me adaptando melhor. Então afetou em todos os sentidos (Cristina, mulher trans, parda, etnia Terena, 40 anos).

Ainda que estejamos numa sociedade em rede e de relações desenvolvidas no espaço digital, a fala revela que o ativismo digital não engloba todas as ações desenvolvidas pelos movimentos. Isso é indicativo de um importante braço dos movimentos sociais que tem por objetivo chegar justamente em pessoas à margem do acesso a bens e serviços essenciais.

Nas entrevistas, destacou-se a importância da articulação em rede durante a pandemia da covid-19, como suporte de solidariedade e apoio entre as pessoas e seus pares. A articulação em rede é apontada como mecanismo para enfrentar o isolamento físico e possíveis agravamentos de questões de saúde mental.

Hoje a saúde mental tá tendo um grande impacto na população LGBT, em todos os sentidos, que a nossa saúde mental está sendo muito preocupante. Então, não é saúde do corpo só, mas a saúde mental tá prejudicando muito (Cristina, mulher trans, parda, etnia Terena, 40 anos).

$\varepsilon$ aí a nível de saúde assim, eu tava conversando com uma colega da Parada [do Orgulho LGBT] que a gente vai perder muita gente, provavelmente pra covid, mas também, pra suicídios assim, que ela 
vem me relatar que algumas pessoas que ela ouviu falar já de três suicídios nesses últimos tempos e aí o que que a gente tá fazendo assim com isso. $O$ que a gente constrói a partir disso né, porque é bem grave assim (Amanda, mulher cisgênera, lésbica, branca, 24 anos).

A literatura nacional aponta efeitos sobre a saúde mental da população em geral, por conta da covid-19, como, tristeza, nervosismo, alterações no sono, especialmente em adultos jovens e mulheres (Barros et al., 2020). Também há indícios na literatura internacional do aumento das vulnerabilidades relativas à saúde mental de pessoas LGBTI por conta da covid-19 (Banerjee; Nair, 2020).

Destacam-se nas entrevistas, os efeitos da pandemia da covid-19 sobre o acesso à prevenção ao HIV/aids. Marcos, que atua como educador de pares em temáticas de prevenção ao HIV e outras ISTs, relatou dois principais efeitos: a percepção de queda da busca por informações sobre HIV e as profilaxias pré e pós-exposição ao HIV (PrEP e PEP); e o impacto sobre a assistência ambulatorial em ISTs.

Pra saber de PEP, PrEP e todas essas coisas, isso diminuiu muito. Eu acho que de alguma maneira a vida sexual das pessoas tá menos ativa, né? $\varepsilon$ nessa questão eu acho que na procura de informações sobre HIV diminuiu bastante.

$\varepsilon$ eu vejo que isso é uma coisa que tá acontecendo meio que geral assim. Em função das pessoas estarem focadas no covid-19 e diminuindo, eu acho, o número de profissionais, então o que tá acontecendo é que umas pessoas em função de outras IST, elas tão ficando um pouco desassistidas (Marcos, homem cisgênero, gay, pardo, 38 anos).

As estratégias de PEP e PrEP são importantes métodos de prevenção combinada ao HIV. No entanto, desde sua implementação. têm encontrado desafios de efetividade nos serviços públicos de saúde brasileiros para atingir populações em situação de maior vulnerabilidade social (Zucchi et al., 2018) ou na adequação e disponibilidade dessas estratégias aos usuários em geral (Kauss et al., 2020). No caso dos atendimentos às ISTs, instaura-se outra lacuna na prevenção combinada, podendo provocar o aumento das situações de risco ao HIV.

Nas falas de algumas entrevistadas, destacou-se a acentuação das vulnerabilidades estruturais sobre as individuais. Tamara, por exemplo, percebe os efeitos da pandemia da covid-19 como mais incisivos em relação à questão étnica.

Como mulher bissexual eu não tenho notado muita diferença na forma de tratamento que a população LGBT tem sofrido, mas como mulher indígena, a pandemia mostrou muita violação de direitos que, não vou dizer que não aconteciam antes as violações de direitos indígenas, porque a gente sabe que é uma coisa que vem de anos. Mas dá para citar como exemplo o caso das crianças Yanomami, que foram infectadas e morreram com o novo coronavírus $e$ as mães não puderam ver os corpos, tipo eles estão desaparecidos sem nenhuma explicação e sem a chance de se despedir como a cultura deles faria. Eu também vi o caso de uma outra mulher indígena que ela tava grávida e ela sofreu um aborto espontâneo e o feto dela foi simplesmente devolvido num vidrinho de soro, coisas desumanas assim. (Tamara, mulher cisgênera, bissexual, parda, etnia Mbya Guarani, 20 anos)

O relato de Tamara expõe violências estatais em relação à saúde indígena. A fala sugere uma omissão estatal permanente, que pode indicar uma tentativa de genocídio e aniquilamento étnico-cultural, marcada pela raça/cor, gênero, classe e etnia. Aqui, torna-se importante um olhar interseccional sobre a produção das vulnerabilidades em relação à saúde da população indígena. No contexto da covid-19, a vulnerabilidade étnica-racial tem sido discutida na literatura (Laurencin; Mcclinton, 2020; Polidoro et al., 2020).

Nesse aspecto, a abordagem das interseccionalidades, inspirada no feminismo negro (Hooks, 200o), ao estabelecer conexões entre marcadores da diferença, como classe, gênero, sexualidade, cor/raça, etnicidade, entre outras, para a análise da produção de opressões e violências, apresenta-se como importante construção teórico-metodológica para compreender situações complexas, como a que foi expressa na fala de Tamara, e em como agir sobre elas. 


\section{0 incremento das violências}

Compreender a temática da violência contra pessoas LGBTI tem sido fundamental para a efetividade do direito à saúde e às políticas de equidade dessa população. Mas, como é possível observar em um estudo recente, os dados sobre a violência que afeta a população LGBTI são preocupantes (Pinto et al., 2020).

Para Cristina, a expulsão de jovens LGBTI, em razão das expressões de gênero e sexualidade, tem sido recorrente. No contexto de pandemia da covid-19, a situação se agrava diante da ausência de acolhimento institucional às pessoas LGBTI no RS.

Em [Cidade Y], da semana passada pra essa, até hoje, terça-feira, eu atendi três casos de expulsão de LGBT da casa dos pais, ou seja, quem é pra acolher, quem é pra amar, tá expulsando os filhos de casa por ser LGBT. Quem vai acolher esses filhos? (Cristina, mulher trans, parda, etnia Terena, 40 anos).

Com exceção de iniciativas pontuais, não há hoje uma estratégia de política pública específica, a nível federal, voltada à assistência social de jovens LGBTI. A sexualidade dos jovens costuma ser silenciada ou tratada sob a ótica do medo, da abstinência sexual e de intervenções negativas (Cornwall; Jolly, 2008). Esse tratamento, no âmbito de uma cultura de ódio contra LGBTI, pode indicar as razões para a expulsão de jovens de suas residências, em razão das expressões de gênero e sexualidade.

Nas entrevistas, destaca-se também a percepção de aumento da violência doméstica contra o gênero feminino durante a pandemia da covid-19.

Só no papel de mulher eu posso dizer o quanto o covid foi um agravante pra violência doméstica também, que a gente sabe que, tendo que manter quarentena em casa, muitas mulheres têm sido agredidas $e$ não têm coragem e acham que não têm também nenhuma rede de apoio pra sair dessa (Tamara, mulher cisgênera, bissexual, parda, 20 anos).

Eu tenho uma rede de advogados, eu tenho filhos jovens adultos e eu sempre digo pra eles: tem sempre que ter o telefone de um delegado, telefone de um policial militar e um advogado, porque é o que acontece, dependendo da delegacia que tu for, dependendo do policial que te abordar, é assim que as coisas funcionam no Brasil e assim que a gente salva a nossa população (Paola, mulher cisgênera, lésbica, negra, 50 anos).

Em razão disso, redes de apoio das áreas de segurança pública e jurídica surgem como elementos fundamentais para o enfrentamento das situações de violência doméstica. Assim como as redes estabelecidas pela sociedade civil organizada revelam-se de grande importância no enfrentamento das violências durante a pandemia da covid-19.

Eu acredito que os movimentos sociais têm uma importância crucial no enfrentamento da pandemia agora, principalmente no ramo da saúde, na saúde das mulheres, porque como eu falei anteriormente tem muito disso da violência também, e a saúde mental das mulheres nesses momentos são desgastadas, $e$ é preciso uma rede de apoio. É preciso de alguém que estenda a mão para essas mulheres. Fora a saúde da mulherno sentindo geral, no sentindo físico, porqueé uma coisa necessária e com o covid-19 muitas coisas têm sido deixadas de lado. (Paola, mulher cisgênera, lésbica, negra, 50 anos)

A agência dos movimentos sociais e dos ativismos, de modo geral, tem sido afetada por um processo de desmantelamento e criminalização das ações (Santos, 2017), tendo sérios desdobramentos sobre áreas como educação e saúde (Miskolci; Pereira, 2019). Contudo, ao encontro da fala acima e no sentido atribuído por Parker (1998), é preciso realçar o papel dos movimentos sociais, especialmente no cenário da covid-19.

\section{Discussão: nova pandemia, velhos desafios}

As experiências individuais revelam como situações enfrentadas pelos entrevistados são ressignificadas na ação coletiva e contribuem para a construção de outras narrativas, tornando-se plataformas para a mobilização comunitária e de transformação social, no sentido atribuído por Parker (1998). Os relatos trazem experiências não 
herméticas, e não individualizadas na sua totalidade, atravessadas por questões de gênero, classe, geração, raça/cor, etnia e sexualidade, na construção de suas plataformas de ação e situando o corpo na dimensão pública. Corpo este, aqui compreendido como fenômeno social, capaz de estabelecer diferentes conexões e intercâmbios sociais (Butler, 2004).

As entrevistas revelam como a pandemia da covid-19 reforçou determinadas vulnerabilidades que afetam a saúde de pessoas LGBTI. Nas entrevistas é possível observar a sobreposição de marcadores da diferença na produção das vulnerabilidades dos sujeitos, indo ao encontro da literatura feminista negra, que demonstra a importância da abordagem interseccional na análise teórico-metodológica (Crenshaw, 2002; Hooks, 200o). Essa abordagem permitiu identificar nas entrevistas a sobreposição de questões de gênero, raça/cor, classe, etnicidade e geração, na produção das vulnerabilidades, acentuada não somente pelo avanço da covid-19, como também por violações já em curso, destacadas na fala de Tamara, de etnia Mbya Guarani. Nesse aspecto, a perspectiva interseccional pode ser uma importante ferramenta para a compreensão da produção de vulnerabilidades e para a ação pública em contextos de crises sanitárias. Nesse sentido, Crenshaw (2002) advoga pelo desenvolvimento de protocolos que venham a romper com os limites da subordinação interseccional, buscando garantir direitos.

Os ativistas têm se deparado com o desafio de reorganizar suas pautas e o agenciamento coletivo, em razão das medidas sanitárias e de um autocuidado, como técnica de defesa, dada a leniência do Estado na implementação de medidas concretas de controle da pandemia da covid-19. Tal reorganização situou boa parte da atuação e articulação dos atores no espaço digital, conservando determinadas ações presenciais. 0 ciberativismo não é compreendido como menos eficaz para mobilização comunitária. A literatura sugere que a "apropriação" de espaços digitais pelos movimentos sociais tem contribuído para o fortalecimento das demandas sociais, ao oferecer novas formas de organização, articulação, descentralização de ações e de fazer política (Deslandes, 2018).

Outrossim, destaca-se a insuficiência das políticas de proteção social às pessoas LGBTI como um dos principais determinantes para a produção de vulnerabilidades na saúde. Na dimensão da política, observa-se que desafios à implementação da PNSLGBT e à integralidade das ações preconizadas para saúde LGBTI já haviam sido apontados pela literatura (Popadiuk; Oliveira; Signorelli, 2017; Silva et al., 2020).

A gente tem acompanhado muito a questão da proteção social como um dos principais determinantes em saúde e a gente nota que as políticas públicas que são construídas nessa área estão cada vez mais distantes da ponta e cada vez sendo menos executadas. (Rosa, mulher cisgênera, heterossexual, branca, 51 anos)

Rosa exerce uma importante atuação em ações de advocacy em questões como: direitos de propriedade intelectual; acesso a medicamentos; elaboração de protocolos de gestão voltados às políticas de equidade na saúde no RS; e ações de ensino e pesquisa. Ela aponta a sobreposição dos problemas que afetam as populações em situação de maior vulnerabilidade e insta a reflexão sobre a necessidade de incrementar respostas intersetoriais para os problemas públicos. Como fator precedente à pandemia da covid-19, ela destaca a precarização do SUS, sendo o maior reflexo dessa situação crítica a Emenda Complementar $\mathrm{n}^{\circ} 95$ (EC 95/2018) vigente. Rosa ilustra como a dimensão estrutural pode afetar a saúde LGBTI, ao problematizar a aprovação da EC $n^{0} 95$, que prejudicou investimentos em educação e saúde.

Eu acho que uma coisa que a gente não pode deixar quando pensar a saúde, seja da população LGBT, seja das pessoas que vivem com aids, seja de qualquer uma das populações que a gente quiser ter um olhar mais detalhado, em função da pandemia também, é o fato que não podemos deixar de pensar a saúde num país que teve uma EC 95. Porque quando a gente teve uma emenda constitucional que fez o congelamento do teto dos gastos e que isso afeta inclusive dentro da área da saúde, [...] isso vai implicar diretamente no que a gente vai conseguir depois que terminar essa pandemia. (Rosa, mulher cisgênera, heterossexual, branca, 51 anos) 
De acordo com uma das entrevistadas, após importantes conquistas normativas para as pessoas LGBTI no Brasil, como a PNSLGBT, instalou-se uma inércia diretamente ligada à implementação das ações: "A política no papel ela é muito legal. Ela traz incômodos e direcionamentos muito bons, só que, em contrapartida a gente não tem gestões que tão preocupadas em implementar a política" (Tamara, mulher bissexual, parda, etnia Mbya Guarani, 20 anos). Nesse aspecto, na percepção da entrevistada, a gestão e a implementação de uma política como a PNSLGBT não são prioridades de governo e Estado.

Ao encontro dos sentidos atribuídos às intervenções sociais por Parker (1998), os movimentos sociais e ativistas, individualmente ou em coletivos, por meio da mobilização comunitária em espaços de sociabilidade presencial ou digital, possuem a capacidade de tensionar por transformações na estrutura social, de forma massiva e intermitente em benefício do interesse público. Nesse sentido, há de se promover a continuidade das ações de ativistas na busca pela efetividade do direito à saúde e de políticas públicas das pessoas LGBTI.

Acredito que o novo coronavírus pegou todos de surpresa, que ele tem sim dificultado a ação dos movimentos sociais, mas ele não parou. Eu acho que ele só tem servido pra gente ver a força que o movimento social tem. A questão da saúde LGBT tem dificultado bastante, mas não é uma dificuldade

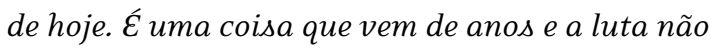
vai parar. Não vai parar agora com a pandemia $e$ não vai parar depois. Em relação à saúde indígena, ela sempre foi um assunto complicado. A luta vem de anos. A luta para conseguir uma saúde especial. Só conseguido mesmo com muita luta e vai ter luta de novo, sim, pra garantir mais direitos e garantir uma melhoria do que já se tem. $\varepsilon$ acredito que as crianças yanonami e os outros parentes indígenas que partiram, eles não morreram, eles viraram semente para luta. (Tamara, mulher cisgênera, bissexual, parda, etnia Mbya Guarani, 2o anos)

\section{Considerações finais}

Este trabalho analisou como a saúde de pessoas LGBTI tem sido afetada durante a pandemia da covid-19, por meio da percepção de ativistas da sociedade civil organizada. No contexto da covid-19, questões relativas à reorganização dos ativismos, à saúde mental de pessoas LGBTI, ao acesso aos serviços de assistência especializada em IST e HIV/ aids, ao aumento de vulnerabilidades em razão de opressões interseccionais e programáticas, sobressaíram nas falas das pessoas entrevistadas.

Devido ao alcance da amostra analisada, buscouse aqui realizar problematizações a respeito das questões suscitadas pelas pessoas entrevistadas, sem a pretensão de qualquer generalização. Sinalizase a importância da continuidade, ampliação e aprofundamento de estudos sobre os efeitos da pandemia da covid-19 sobre a saúde da população LGBTI, considerando as interseccionalidades do fenômeno e a relação com a violência, pobreza, entre outras questões que intensificam a vulnerabilidade social dessa população. Constata-se a importância da perspectiva interseccional como ferramenta para a compreensão da produção das vulnerabilidades e para a ação pública em contextos de crises sanitárias.

No cenário de redemocratização do Brasil, com a promulgação da Constituição Federal de 1988 e a criação do SUS, a epidemia de aids irrompeu provocando a mobilização comunitária de diversos ativistas LGBTI. Importa reconhecer que, em momentos difíceis e de ausência do Estado, a sociedade civil organizada se faz presente na articulação de ações, no estabelecimento de redes e na pressão social em defesa do interesse público. Em diferentes espaços de atuação, movimentos sociais e ativistas são atores essenciais nos regimes democráticos, na garantia e promoção do direito a saúde, suporte e implementação de políticas públicas.

\section{Referências}

ANDRADE, J. et al. Vulnerabilidade de mulheres que fazem sexo com mulheres às infecções sexualmente transmissíveis. Ciência \& Saúde Coletiva, Rio de Janeiro, v. 25, n. 10, p. 3809-3819, 2020.

BANERJEE, D.; NAIR, V. S. "The untold side of covid-19": struggle and perspectives of the sexual minorities. Journal of Psychosexual Health, Thousand Oaks, v. 2, n. 2, p. 113-120, 2020. 
BARROS, M. B. de A. et al. Relato de tristeza/ depressão, nervosismo/ansiedade e problemas de sono na população adulta brasileira durante a pandemia de covid-19. Epidemiologia e Serviços de Saúde, Brasília, DF, v. 29, p. e2020427, 2020.

BUTLER, J. Undoing gender. Abingdon: Routledge, 2004.

CORNWALL, A.; JOLLY, S. Introdução: a sexualidade é importante. In: CORNWALL, A.; JOLLY, S. Questões de sexualidade: ensaios transculturais. Rio de Janeiro: ABIA, 2008, p. 29-48.

CRENSHAW, K. Documento para o encontro de especialistas em aspectos da discriminação racial relativos ao gênero. Revista Estudos Feministas, Florianópolis, v. 10, n. 1, p. 171-188, 2002.

DESLANDES, S. F. 0 ativismo digital e sua contribuição para a descentralização política. Ciência \& Saúde Coletiva, Rio de Janeiro, v. 23, p. 3133-3136, 2018.

GOHN, M. da G. Social movements in contemporary. Revista Brasileira de Educação, Rio de Janeiro, v. 16, n. 47, p. 333-361, 2011.

GRANGEIRO, A.; SILVA, L. L. da; TEIXEIRA, P. R. Resposta à aids no Brasil: contribuições dos movimentos sociais e da reforma sanitária. Revista Panamericana de Salud Pública, Washington, DC, v. 26, n. 1, p. 87-94, 2009.

HINE, C. Ethnographies of online communities and social media: modes, varieties, affordances. In: FIELDING, N. G.; LEE, R. M.; BLANK, G. (Ed.). The SAGE handbook of online research methods. Thousand Oaks: SAGE , 2008. p. 257-270.

HOOKS, B. Feminism is for everybody: passionate politics. Cambridge South End Press, 2000.

KAUSS, B. et al. Reincidentes en el cuidado, pero sin derecho a la prevención: un análisis de la oferta de la profilaxis posexposición sexual al VIH en Porto Alegre, Brasil. Salud Colectiva, Buenos Aires, v. 16, p. e2463, 2020.

LATOUR, B. Reagregando o social: uma introdução à teoria do ator-rede. Salvador: Edufba, 2012.

LAURENCIN, C. T.; MCCLINTON, A. The covid-19 pandemic: a call to action to identify and address racial and ethnic disparities. Journal of Racial and Ethnic Health Disparities, New York, v. 7, n. 3, p. 398-402, 2020.

MACHADO, J. A. S. Network activism and identity connections: new perspectives for social movements. Sociologias, Porto Alegre, n. 18, p. 248-285, 2007.

MATEBENI, Z. et al. All sexed up: a resposta de mulheres lésbicas negras jovens ao sexo (mais) seguro em Johannesburg, África do Sul. Physis: Revista de Saúde Coletiva, Rio de Janeiro, v. 19, n. 2, p. 333-348, 2009.

MELLO, L.; AVELAR, R. B. de; MAROJA, D. Por onde andam as políticas públicas para a população LGBT no Brasil. Sociedade e Estado, Brasília, DF, v. 27, n. 2, p. 289-312, 2012.

MISKOLCI, R.; PEREIRA, P. P. G. Educação e Saúde em disputa: movimentos anti-igualitários e políticas públicas. Interface: Comunicação, Saúde, Educação, Botucatu, v. 23, 2019.

OEA Organização dos Estados Americanos. A CIDH insta os Estados a garantirem os direitos das pessoas LGBTI em resposta à pandemia da COVID-19. Comissão Interamericana de Direitos Humanos, Washington, DC, 20 abr. 2020. Disponível em: <https://www.oas.org/pt/cidh/prensa/ notas/2020/o81.asp>. Acesso em: 20 out. 2020.

PARKER, R. Teorias de intervenção e prevenção do HIV/Aids. In: PARKER, R.; TERTO JUNIOR, V. de S. (Ed.). Entre homens: homossexualidade e aids no Brasil. Rio de Janeiro: ABIA, 1998. p. 101-109.

PINTO, I. V. et al. Perfil das notificações de violências em lésbicas, gays, bissexuais, travestis e transexuais registradas no Sistema de Informação de Agravos de Notificação, Brasil, 2015 a 2017. Revista Brasileira de Epidemiologia, São Paulo, v. 23, p. 1-13, 2020.

POLIDORO, M. et al. Territories under siege: risks of the decimation of indigenous and quilombolas peoples in the context of covid-19 in South Brazil. Journal of Racial and Ethnic Health Disparities, New York, p. 1-11, 16 set. 2020.

POPADIUK, G. S.; OLIVEIRA, D. C.;

SIGNORELLI, M. C. A política nacional de 
saúde integral de Lésbicas, Gays, Bissexuais E

Transgêneros (LGBT) e o acesso ao processo transexualizador no Sistema Único de Saúde (SUS): avanços e desafios. Ciência \& Saúde Coletiva, Rio de Janeiro, v. 22, n. 5, p. 1509-1520, 2017.

SANTOS, M. F. C. Ideologia da punição, penalização e criminalização em políticas de combate a violações de direitos: paradoxos das lutas por reconhecimento e direitos humanos. Psicologia Política, São Paulo, v. 17, n. 38, p. 35-43, 2017.

SILVA, A. de C. A. da et al. Implementação da política nacional de saúde integral de lésbicas, gays, bissexuais, travestis e transexuais (PNSI LGBT) no Paraná, Brasil. Interface: Comunicação, Saúde, Educação, Botucatu, v. 24, 2020.

TREVISAN, J. S. Devassos no Paraíso: a homossexualidade no Brasil, da colônia à atualidade. 4. ed. Rio de Janeiro: Objetiva, 2018. UN - UNITED NATIONS. Independent Expert on protection against violence and discrimination based on sexual orientation and gender identity. United Nations, New York, 2020. Disponível em: <https://www.ohchr.org/EN/Issues/ SexualOrientationGender/Pages/COVID19Report. aspx>. Acesso em: 20 out. 2020.

WU, F. et al. A new coronavirus associated with human respiratory disease in China. Nature, London, v. 579, n. 7798, p. 265-269, 2020.

YANOW, D. Qualitative-interpretive methods in policy research. In: FISCHER, F.; MILLER, G. J. Handbook of public policy analysis: theory, politics, and methods. Abingdon: Routledge, 2007. p. 405-415.

ZUCCHI, E. M. et al. Da evidência à ação: desafios do Sistema Único de Saúde para ofertar a profilaxia pré-exposição sexual (PrEP) ao HIV às pessoas em maior vulnerabilidade. Cadernos de Saúde Pública, Rio de Janeiro, v. 34, n. 7, p. 1-16, 2018.

\section{Contribuição dos autores}

Kauss participou da concepção do manuscrito original, interpretação, redação e revisão final do texto. Polidoro, Costa e Canavese colaboraram na interpretação, redação e revisão final do texto.

Recebido: 12/4/2021

Aprovado: 3/5/2021 